ORIGINAL PROF-2300

\title{
ACUTE BRONCHIOLITIS IN CHILDREN;
}

EPIDEMIOLOGIC AND CLINICAL FEATURES

\author{
Dr. Shakil Ahmad, Dr. Sadida Aamir, Dr. Shahbaz Ahmad
}

ABSTRACT... Objectives: To study the epidemiological and clinical features of acute bronchiolitis in children $<2$ years of age with mild to moderate acute bronchiolitis. Study design: Descriptive, cross sectional study. Place and duration of study: Outpatient department of Department of Pediatrics, independent university hospital, Faisalabad, Pakistan, from October 2010 to March 2011. Methodology: 200 children diagnosed clinically with mild or moderate acute bronchiolitis were included in the study using convenient sampling technique. Epidemiologic variables of interest included age, gestational age at birth, sex, weight, breastfed or not, parental or caregiver tobacco smoking and socioeconomic status. Clinical variables of interest included cough, fever, breathlessness, wheeze, Rhonchi, feeding and sleep pattern and severity of disease. Results: Predominant age group was between 2 to 12 months (76.5\%) with mean age of 7.6 44.7 . $95.5 \%$ of children were full term at birth. Male predominance with male to female ratio of $1.4: 1$ was noted. Mean weight was $7.2 \pm 1.8 \mathrm{~kg}$. Predominantly mixed feeding pattern (45\%) was observed. Most of the parents/caregivers (70\%) were nonsmokers. Majority of children $(81.5 \%)$ belonged to families with poor socioeconomic status. Results of clinical variables revealed Cough (100\%), breathlessness $(69.5 \%)$, audible wheeze (59.5\%) and rhonchi on chest auscultation (100\%), disturbed sleep (80\%) and decreased oral feeding $(78 \%)$. Majority of children $(79.5 \%)$ were afebrile. Mild acute bronchiolitis $(73.5 \%)$ was predominant as compared to moderate acute bronchiolitis (26.5\%). Conclusions: Acute bronchiolitis is more prevalent in children $<1$ year of age with male predominance and in children from families with poor socioeconomic status. Mild form of acute bronchiolitis is more common. A relative lack of fever along with cough, breathlessness, wheeze and/or rhonchi are major presenting clinical features of acute bronchiolitis.

Key words: Bronchiolitis, children, epidemiology

Article Citation

Ahmad S, Aamir S, Ahmad S. Acute Bronchiolitis In Children; Epidemiologic and clinical features. Professional Med J 2013;20(5): 707-712.

\section{INTRODUCTION}

Bronchiolitis is an acute, highly contagious and a seasonal viral illness of lower respiratory tract characterized by first episode of acute wheeze along with mild or no fever, nasal discharge, dry wheezy cough, increased respiratory effort, fine inspiratory crackles and/or high-pitched expiratory wheeze in children less than 2 years of age. Acute bronchiolitis is a clinical diagnosis. It is generally a self-limiting disease. Cough, breathlessness and wheeze are major presenting symptoms. For management purposes, it is categorized as mild, moderate and severe based on a clinical criterion. Respiratory syncytial virus (RSV) is responsible for about $80 \%$ of cases $^{1-9}$.

The burden of disease is significant. Acute bronchiolitis is the most common cause of lower respiratory tract infection in the first year of life. Worldwide, Bronchiolitis is a significant cause of respiratory disease. According to the World Health Organization bulletin, an estimated 150 million new cases occur annually; $11-20$ million (7-13\%) of these cases are severe enough to require hospital admission. Worldwide, $95 \%$ of all cases occur in developing countries.

Epidemiologic data for underdeveloped countries are incomplete. Epidemiologic data from underdeveloped countries show that RSV is a predominant viral cause of acute lower respiratory tract infections and accounts for about $65 \%$ of hospitalizations due to viruses. However, less is known about RSVassociated mortality in developing countries. Morbidity and mortality may be higher in lessdeveloped countries because of poor nutrition and lack of resources for supportive medical care ${ }^{10-11}$. The frequency of bronchiolitis in developed countries appears to be similar to that in the United States. In 
United States of America, among healthy, full term infants, $80 \%$ of hospitalizations occur in children $<1$ year of age with $50 \%$ of hospitalizations occurring in children $<3$ months of age $^{12}$. In Pakistan, acute respiratory illness (ARI) is the leading cause of death in young children responsible for $20-30 \%$ of all childhood deaths under 5 years of age ${ }^{13-15}$.

Bronchiolitis usually affects children younger than 2 years, with a peak incidence in infants aged 2-8 months. About $75 \%$ of cases of bronchiolitis occur in children younger than 1 year and 95\% in children younger than 2 years. Bronchiolitis occurs 1.25 times more frequently in males than in females. Boys are 1.25 times more likely to be admitted than girls. Death is 1.5 times more likely in males. Seasonal occurrence is a characteristic feature with peak prevalence in the winter months (November to March). Re-infection during a single season is possible ${ }^{16-19}$.

Host and environmental factors related to disease severity include prematurity, age $<6$ months, congenital heart disease, bronchopulmonary dysplasia, cystic fibrosis, immune deficiency, poverty, crowding, exposure to tobacco smoke, and malnutrition. Factors that increase incidence of infection include young age, multiple gestation, family history of atopy, lack of parental education, household crowding, lack of breastfeeding, older school age siblings, daycare attendance, passive smoke exposure, and discharge from a neonatal intensive care unit between October and March ${ }^{20-24}$.

Few regional and local studies are available regarding various epidemiologic and clinical features of acute bronchiolitis in children. We planned this descriptive study to observe epidemiological and clinical features of acute bronchiolitis in children $<2$ years of age presenting at Independent University Hospital Faisal Abad Pakistan.

\section{METHODS}

This descriptive, cross sectional study was conducted by department of pediatrics in collaboration with department of community medicine at outpatient department (OPD) of Independent University Hospital Faisal Abad Pakistan. The objective of our study was to observe epidemiologic and clinical features of acute bronchiolitis in children $<2$ years of age with mild to moderate acute bronchiolitis. Duration of study was 6 months from October 2010 to March 2011. During this time period, seven thousand and two hundred children were seen in pediatrics OPD. Out of these, two hundred and seventy two children were diagnosed with acute Bronchiolitis.

Diagnosis of acute bronchiolitis and its further categorization into mild, moderate and severe forms was based on a clinical criterion 9 . Any child $<2$ years of age with first episode of acute wheeze along with mild or no fever, nasal discharge, dry or moist wheezy cough, increased respiratory effort, fine inspiratory crackles and/or high-pitched expiratory wheeze was diagnosed as a case of acute bronchiolitis. Children with age $\geq 3$ months, feeding and sleeping well, respiratory rate $<50$, no or minimal respiratory distress, no risk factors for severe disease, Oxygen saturation $>95 \%$ in air were categorized as mild bronchiolitis. Children with feeding and sleep pattern less than usual, some/intermittent irritability, no risk factors for severe disease, Respiratory rate $50-70$, mild to moderate respiratory distress and oxygen saturation $92-95 \%$ in air were categorized as moderate bronchiolitis. Children with Irritability and/or lethargy, ill/toxic looks, poor feeding, moderate or severe respiratory distress or apnea, risk factors for severe disease (Preterm, Poverty, Age less than 6 weeks, Overcrowding, Congenital heart disease, Chronic respiratory disease, Exposure to tobacco Smoke, Malnutrition, Immune deficiency) and oxygen saturation $<92 \%$ were categorized as severe bronchiolitis. 
A sample of 200 children diagnosed clinically with mild or moderate bronchiolitis was collected by convenient sampling. Detailed history and physical examination along with complete blood counts and chest $\mathrm{x}$-rays to rule out differential diagnosis, was carried out in each case. Neonates, children with severe acute bronchiolitis, alternative diagnosis like pneumonia, pulmonary tuberculosis, bronchial asthma, personal or family history of atopy and congenital heart disease were excluded from the study.

Informed consent was taken from parents and/or caregivers in each case and confidentiality was assured. Families with monthly income of Rupees $\leq 5000$ - were categorized as poor.

Epidemiologic variables of interest included age, gestational age at birth, sex, weight, breastfed or not, parental or caregiver tobacco smoking and socioeconomic status. Clinical variables of interest included cough, fever, breathlessness, wheeze, Rhonchi, feeding and sleep pattern and severity of disease.

Data collected was recorded in a structured Performa. The data was analyzed using IBM SPSS V-19 computer software and was presented as frequency tables.

\section{RESULTS}

Results of epidemiologic and clinical features of 200 children with acute bronchiolitis are summarized in tables 1 and 2. Majority of children were cases of mild acute bronchiolitis $(73.5 \%)$ as compared to moderate acute bronchiolitis (26.5\%). Predominant age group was between 2 to 12 months $(76.5 \%)$ with mean age of $7.6 \pm 4.7 .95 .5 \%$ of children were full term at birth. Comparison of disease severity with age showed that out of 53 children $(26.5 \%)$ with moderate acute bronchiolitis, $81 \%$ (43/53) were $<1$ year of age. Male predominance with male to female ratio of 1.4:1 was noted. Mean weight was $7.2 \pm 1.8 \mathrm{~kg}$. Predominantly mixed feeding pattern (45\%) was observed. Most of the parents/caregivers (70\%) were nonsmokers.

\begin{tabular}{|c|c|}
\hline Variable & Number (\%) \\
\hline \multicolumn{2}{|l|}{ Age } \\
\hline 2-12 months & $153(76.5)$ \\
\hline 13-24 months & $47(23.5)$ \\
\hline \multicolumn{2}{|l|}{ Mean age $(7.6 \pm 4.7)$} \\
\hline \multicolumn{2}{|l|}{ Sex } \\
\hline Male & $117(58.5)$ \\
\hline Female & $83(41.5)$ \\
\hline \multicolumn{2}{|l|}{ Gestational Age } \\
\hline Term & $191(95.5)$ \\
\hline Preterm & $09(4.5)$ \\
\hline \multicolumn{2}{|l|}{ Weight } \\
\hline $0-9 \mathrm{kgs}$ & $160(80)$ \\
\hline $10-12 \mathrm{kgs}$ & $40(20)$ \\
\hline \multicolumn{2}{|c|}{ Mean weight $(7.2 \pm 1.8)$} \\
\hline \multicolumn{2}{|l|}{ Feeding pattern } \\
\hline Breast-fed & $62(31)$ \\
\hline Bottle-fed & $48(24)$ \\
\hline Mixed & $90(45)$ \\
\hline \multicolumn{2}{|c|}{ Parental / caregiver tobacco smoking } \\
\hline Smoker & $60(30)$ \\
\hline Non smoker & $140(70)$ \\
\hline \multicolumn{2}{|c|}{ Socioeconomic status } \\
\hline Poor & $163(81.5)$ \\
\hline Not poor & $37(18.50$ \\
\hline
\end{tabular}


Majority of children (81.5\%) belonged to families with poor socioeconomic status.

Cough (100\%), breathlessness (69.5\%), audible wheeze $(59.5 \%)$ and rhonchi on chest auscultation $(100 \%)$ were predominant clinical features along with disturbed sleep (80\%) and decreased oral feeding (78\%). Majority of children (79.5\%) were afebrile.

\section{DISCUSSION}

Worldwide, acute bronchiolitis is a significant and common seasonal viral illness of lower respiratory tract in infants and children <2 years of age. Numerous studies have been and are being conducted to enhance our understanding of epidemiologic and clinical aspects of acute bronchiolitis to provide evidence based preventive and therapeutic guidelines.

Iqbal S. M. J., Afzal M. F., Sultan M. $\mathrm{A}^{25}$ conducted a similar study which included 107 children diagnosed clinically with acute bronchiolitis. Majority of children $(57.9 \%, 62 / 107)$ were between $2-12$ months age group with mean age of $11.3 \pm 5.6$. This is comparable to our study in which $76.5 \%$ children (153/200) were between 2-12 months age group with mean age of $7.6 \pm 4.7$. This lower mean age can be attributed to comparatively large sample size in our study. Bottle feeding $(48 \%, 51 / 107)$ was predominant feeding pattern in their study, though in our study mixed feeding predominance $(45 \%$, $90 / 200$ ) was observed. Observations of male sex predominance $(57 \%, 61 / 107,1.3: 1)$ and predominance of poor socioeconomic class $(62 \%$, $66 / 107$ ) are similar and comparable to our study. Clinical parameters in their study showed higher prevalence of breathlessness (91\%), wheezing $(72 \%)$ and fever $(64 \%)$. These findings are similar to our study but fever was noted in only 20\% (41/200) children in our study. They reported a normal feeding pattern in $68 \%$ of cases whereas in our study

\begin{tabular}{|c|c|}
\hline Variable & Number (\%) \\
\hline \multicolumn{2}{|l|}{ Disease severity } \\
\hline Mild & $147(73.5)$ \\
\hline Moderate & $53(26.5)$ \\
\hline \multicolumn{2}{|l|}{ Fever } \\
\hline Present & $41(20.5)$ \\
\hline Not present & $159(79.5)$ \\
\hline \multicolumn{2}{|l|}{ Cough } \\
\hline Present & $200(100)$ \\
\hline Not present & - \\
\hline \multicolumn{2}{|l|}{ Breathlessness } \\
\hline Present & $139(69.5)$ \\
\hline Not present & $61(30.5)$ \\
\hline \multicolumn{2}{|l|}{ Wheeze } \\
\hline Audible & $119(59.5)$ \\
\hline Not audible & $81(39.5)$ \\
\hline \multicolumn{2}{|l|}{ Rhonchi } \\
\hline Audible & $200(100)$ \\
\hline Not audible & - \\
\hline \multicolumn{2}{|l|}{ Feeding } \\
\hline Decreased & $156(78)$ \\
\hline Normal & $44(22)$ \\
\hline \multicolumn{2}{|l|}{ Sleep } \\
\hline Distributed & $160(80)$ \\
\hline Normal & $40(20)$ \\
\hline
\end{tabular}

decreased feeding $(78 \%)$ and disturbed sleep (80\%) was noted. Their study did not categorize bronchiolitis patients by severity.

Arif A, Tajammul $\mathrm{A}^{26}$ conducted a similar study 
focused primarily on clinical aspects of bronchiolitis using a relatively small sample size of 85 children as compared to our study. They also diagnosed bronchiolitis clinically. Their observations of higher bronchiolitis prevalence in younger age group (mean $6.9 \pm 3.4$ months), male to female ratio of 1.3 with an overall male predominance $(68 \%)$, respiratory distress (97.5\%) and wheezing (98.7\%) are consistent with our study. They observed a higher prevalence of bronchiolitis (66\%) in breastfed infants where as in our study mixed feeding pattern (45\%, 90/200) predominated. Their study also did not categorize bronchiolitis cases by severity.

The major limitation of our study was the lack and non availability of etiologic diagnosis of acute bronchiolitis. Diagnosis of acute bronchiolitis and its further categorization into mild, moderate and severe forms was based on a clinical criterion.

\section{CONCLUSIONS}

On the basis of epidemiologic and clinical observations made in our study, we conclude that acute bronchiolitis is more prevalent in children $<1$ year of age with male predominance and in children from families with poor socioeconomic status. Mild form of acute bronchiolitis is more common. A relative lack of fever along with cough, breathlessness, wheeze and/or rhonchi are major presenting clinical features of acute bronchiolitis.

\section{Copyright(C) 15 July, 2013.}

\section{REFERENCES}

1. Andrew Bush, Anne H Thomson. Acute bronchiolitisclinical review: BMJ 2007; 335:1037-41.

2. Maud Meates, Dennis. Bronchiolitis-best practice: Arch Dis Child Educ PractEd 2005; 90:ep81-ep86.

3. Smyth RL, Openshaw PJM. Bronchiolitis. Lancet. 2006; 368(9532):312-322.

4. Joseph J. Zorc and Caroline Breese Hall. Bronchiolitis: Recent Evidence on Diagnosis and Management:
Pediatrics 2010;125;342-349.

5. American Academy of Pediatrics Subcommittee on Diagnosis and Management of Bronchiolitis: Diagnosis and management of bronchiolitis. Pediatrics 2006; 118:1774-1793.

6. Long SS, Pickering LK, Prober CG. Principles and Practice of pediatric Infectious Diseases. 2 Ed. New York: Churchill Livingstone; 2003.

7. Kliegman RM, Stanton BF, Geme JWS. Nelson textbook of pediatrics. 19th Ed. Philadelphia: Elsevier; 2011.

8. Hay WM, Levin MJ, Sondheimer JM. Current Diagnosis \& Treatment: Pediatrics (CDTP). 20th Ed. Colorado: McGraw-Hill; 2010.

9. Mulholland EK, Olinsky A, Shann FA. Clinical findings and severity of acute bronchiolitis. Lancet 1990; 335(8700):1259-61.

10. Hall CB, Weinberg GA, Iwane MK, et al. The burden of respiratory syncytial virus infection in young children. N Engl J Med. Feb 5 2009; 360(6):588-98.

11. Deshpande SA, Northern V. The clinical and health economic burden of respiratory syncytial virus disease among children under 2 years of age in a defined geographical area. Arch Dis Child 2003; 88:1065-9.

12. Law BJ, Carbonell-Estrany X, Simoes EAF. An update on respiratory syncytial virus epidemiology: a developed country perspective. Respir Med 2002; 96:S1-7.

13. Khan TA, Madni SA, Zaidi AK. Acute respiratory infection in Pakistan: have we made any progress? J Coll Physicians Surg Pak 2004; 14: 440-8.

14. Rani R, Qazi SA, Rehman GN, Mushtaq A Khan MA. ARI case management in a community. Pakistan Ped $\mathrm{J}$ 1995; 19: 9-13.

15. Sarfraz T. Acute respiratory infections in children. Pak Armed Forces Med J 1996; 46: 28-32.

16. Tsolia MN, Kafetzis D, Danelatou K, et al. Epidemiology of respiratory syncytial virus bronchiolitis in 
hospitalized infants in Greece. Eur J Epidemiol. 2003; 18(1):55-61.

17. Rathore AW, Randhawa SM, Quratul Ain, Sajid M. Wheezing conditions in early childhood: prevalence and risk factors among preschool children. Ann King Edward Med Coll 2005; 11: 14-6.

18. Handforth J, Friedland JS, Sharland M. Basic epidemiology and immunopathology of RSV in children. Paediatric Respiratory Reviews 2000; 1:210-14.

19. R. Y. T. Sung, R. C. K. Chan, J. S. Tam, A. F. B. Cheng and H. G. S. Murray. Epidemiology and etiology of acute bronchiolitis in Hong Kong Infants Epidemiol. Infect. (1992), 108, 147-154.

20. Welliver RC. Review of epidemiology and clinical risk factors for severe respiratory syncytial virus (RSV) infection. J Pediatr.2003; 143(5 suppl):S 112-S117.

21. Jansson L, Nilsson P, Olsson M. Socioeconomic Environmental factors and hospitalization for acute bronchiolitis during infancy. Acta Paediatr. 2002; 91(3):335-338.

22. Holberg CJ, Wright AL, Martinez FD, Ray CG, Taussig LM, Lebowitz MD. Risk factors for respiratory syncytial virus associated lower respiratory illnesses in the first year of life. Am J Epidemiol. 1991; 133(11):1135-1151.

23. Blizzard LP, Ponsonby A-LP, Dwyer TMD, et al. Parental smoking and infant respiratory infection: how important is not smoking in the same room with the baby? Am J Public Health 2003; 93:482-8.

24. Gurkan F, Kiral A, Dagli E, et al. The effect of passive smoking on the development of respiratory syncytial virus bronchiolitis. Eur J Epidemiol 2000; 16:465-8.

25. Iqbal SMJ, Afzal MF, Sultan M A. Acute Bronchiolitis: Epidemiological and Clinical Study. Ann King Edward Med Coll 2009; 15: 203-5.

26. Arif A, Tajammul A. Acute bronchiolitis: A clinical study. Pak Ped J 1998; 22: 175-7.

\section{AUTHOR(S):}

1. DR. SHAKIL AHMAD

FCPS (Paediatrics)

Assistant Professor

Independent Medical College, Faisalabad.

2. DR. SADIDA AAMIR

FCPS (Paediatrics)

Assistant Professor

Independent Medical College, Faisalabad.

3. DR. SHAHBAZ AHMAD

MBBS, MPH

Assistant Professor Community Medicine Independent Medical College, Faisalabad.
Correspondence Address:

Dr. Shakil Ahmad

FCPS (Paediatrics)

Assistant Professor

Independent Medical College, Faisalabad.

shakeel.72@hotmail.com

\section{PREVIOUS RELATED STUDIES}

Nadeem Hashmat, Naureen Kanwal, Mohammad Asghar Butt, Bushra Abdul Malik, Saif-Ullah Sheikh. BRONCHIOLITIS WITH MOTELUKAST; TO DETERMINE IMPROVEMENT IN SYMPTOMS IN 02 MONTHS TO 02 YEARS OLD CHILDREN (Original) Prof Med Jour 17(4) 568-572 Oct, Nov, Dec 2010. 